\title{
RELATIONSHIP BETWEEN ADVERSE LIFE EVENTS ON SURVIVED SUICIDE ATTEMPTER'S IN A RURAL POPULATION OF TERTIARY CARE CENTER, SOUTH INDIA
}

\author{
Nagaraja G. M12, Mohan Reddy M², Lakshmaiah V³, Ravishankar S4.
}

1. Assistant Professor, Department of Sociology, Sri Devaraj Urs Academy of Higher Education and Research

2. Professor and Head, Department of Psychiatry, Sri Devaraj Urs Academy of Higher Education and Research

3. Professor of Medicine \& Medical Superintendent, Sri Devaraj Urs Academy of Higher Education and Research

4. Assistant Professor, Department of Bio-Statistics, Sri Devaraj Urs Academy of Higher Education and Research

\section{CORRESPONDING AUTHOR:}

Dr. Mohan Reddy.M,

Professor \& HOD,

Department of Psychiatry,

RLJH \& RC.

E-mail: drmmrpsy@yahoo.co.in

\section{HOW TO CITE THIS ARTICLE:}

Nagaraja GM, Mohan Reddy M, Lakshmaiah V, Ravishankar S. "Relationship between adverse life events on survived suicide attempter's in a rural population of tertiary care center, south India”. Journal of Evolution of Medical and Dental Sciences 2013; Vol2, Issue 26, July 1; Page: 4710-4718.

ABSTRACT: Studies from south India have reported high rates of suicide. We aim to understand the Socio-demographic factors methods and reasons for suicidal attempts. 109 Patients with history of attempted suicides were admitted to R. L. Jalappa Hospital Kolar, a tertiary care center. Of these 65patients survived and various methods of committing suicide included poisoning 47 cases, hanging 9cases, and alcohol and tablets consumption 29 cases, overdose of sleeping pills 19 cases. 24 Students involved in the study attempted hanging, poisoning, slit throat. METHODS: Structured Questioners was administered to the subjects relating to the factors responsible for attempted suicide and survived. RESULTS: In this study a total of 109 patients are admitted survived 65, death 31, Discharge against medical advice or not affordable 16.Peak occurrence of suicidal attempts was found in the second and third decades (15-35years). Suicidal attempts among Hindu constituted about $81.65 \%$. Among females illiterates are 69.5\%. Agricultures 55.04\%,Housewifes are $14.67 \%$,students $22.01 \%$, Eighty two percent of the subject were rural background and $17.43 \%$ are nuclear families and no income group are 36.69\% attempters. CONCLUSION: Our study reveals that people perceived suicide as an option to overcome interpersonal, financial stress, family problems, love affair and fear of failure in the examinations. Suicide and attempt suicide are slowly occupying the higher position of a public health problem caused by multiple factors and the age group of 16 - 45 years, male sex, low education level, low socioeconomic status, illness and family problems are more prone to attempt suicide. Among these most of them are preventable and controllable.

KEY WORDS: Suicide, NCRB, Alcohol, Pesticide consumption 
INTRODUCTION: Suicide among young people has emerged as a major public health and clinical issue in many low and middle income countries, Suicide is mass great retreat from life.[1] The motives underlying suicidal acts are numerous and complex. The importance of social influences can easily be exaggerated and influences of group motives of suicide under various factors are physical pain including frustration of instinctive demands, social sufferings and fears doubts and dreads [2]. Sociologist Durkheim says that suicide is widely belief to be an individual act, but a function of the individual and the society. Durkheim argued that particular circumstances could lead to a person taking his or her life, but personal reason may not adequately explain suicide for anonymity and impersonality, making may people to become isolated from the family and friends, and this could lead to frustration and suicide [3].

The world's most ruthless killer and the greatest cause of suffering on earth is extreme poverty. Poverty as a variable adversely influencing on health poverty is a multidimensional phenomenon, encompassing inability to satisfy basic needs lack of control over resources, lack of education and poor health. Poverty can be intensely alienating and distressing and if particular concerns are the direct and indirect effects of poverty [1]. The development and maintenance of emotional, behavioral and psychiatric problems, in developing countries are quite different. The substances most commonly used are self-poisoning. Many studies have reported that low socioeconomic status is associated with high prevalence of mood disorders and stress of poverty may be causally related to depression. People who attempt suicide belong more often to the social categories associated with social destabilization and poverty. An attempt commit suicide is a crime. The Indian penal code upholds the dignity of human life, because human life is as precious to the state as it is, to the holder and state cannot turn a blind eye to a person in attempting to kill himself [4].

India has a population size comparable to that of china, and also estimates suicide rates based on a sample of the population. In India, however, suicide is illegal so there is an even greater danger of under reporting. Although the police investigate all suspected suicide cases, before final verdict is passed the case is reviewed by 'Panchayatdars', who are prominent citizens in the locality and neighbors' of the deceased. Many deaths in the rural areas are not registered at all, partly because of an inefficient registration system and partly because families fear the social and legal consequences associated with suicides.

National Crime Record Bureau, 2010, the official agency responsible for suicide data collection in India, Karnataka, Kerala, Tamil Nadu a south India state has the highest suicide rate among Indian states. In 2010 Karnataka 21.5/1000, Tamil Nadu 24.5/1000, Kerala 24.6/1000 Sikkim 45.9/1000, Pondicherry 45.5/1000, Nagaland 0.5/1000, the national average being $11.4 / 1000$ [5]

OBJECTIVES: To study the socio-demographic factors, methods and reason for attempted suicides among the survivors.

METHODS: A retrospective Observational study from July 2010 to June 2011 of all admitted patients of deliberate self-harm at Intensive Care Unit of R. L. Jalappa Hospital and Research Center, Kolar was done to examine the socio-demographic profile and clinical outcome of suicidal behavior. Data were collected from 65 patients using structured questionnaire. A total of 109 patients 
admitted to the intensive care unit consented for the participation in the study. A total number of 44 attempters was excluded from the study either due to refuse to take part in the study or discharged against medical advice or they cannot bear the expense. Remaining 65 attempters gave their consent and constituted the study group. The data thus obtained and compiled and analyzed. The following findings on survived suicidal behavior and associated factors were observed [6].

RESULTS: Of the 109 suicidal attempters studied 61(55.96\%) were males and 48 (44.03\%) females which gave male to female ration of 1.6:1. The age of 16-25 years male attempters was 27 (24.27\%) female $14(12.84 \%)$ higher than that of females. The youngest attempters were of 15years age and the oldest were of 66years. Peak occurrence of suicidal attempts was found in the second and third decades (16-35years) and it was least in the sixth decade.

DISCUSSION: Hindus constituted 81.65\%, Muslims 13.76\%, Christian 4.58\% in our study. This may be due to the large Hindu population residing in rural area. Almost (60.30\%) of the subjects had not received any education. Almost half of study group (36.69\%) of suicidal attempters had education from matriculation up to college. Among suicide attempters $82.56 \%$ resided in rural India, $17.43 \%$ in urban as per our study. Most of the 65 suicidal attempters were from the lower (classes IV and V) socio economic groups. The number of suicidal attempters increased gradually with decrease in socio economic status. The total sample comprised about $55.04 \%$ of agriculturist, housewives $14.67 \%$, more number of males than females attempted suicide, $22.01 \%$ of student's are suicide attempters. According to our study 65 patient are survived from suicide [7].

Separate interviews with some of the ICU patients suggested physical and mental humiliation and torture by alcoholic husbands or in laws that prompted them to attempt suicide. Social support for women in general is inadequate, especially in rural areas. We believe that these factors have a strong role in enhancing vulnerability to suicide attempt among married woman [8]. The number of men attempting suicide also peaked during (May, July, august) this period though women out numbered this seasonal trend for attempter's points towards ecological factors. Agricultural work, increases during this period. The easy availability of pesticides, other studies of rural communities have reported similar findings [6]. Ignorance and carelessness about safe storage allows easy access to these lethal poisons in the household, marital disharmony, family conflict, conflict with newly married spouse was the commonest cause in both sexes followed by quarrel with in-laws [9], guardians, husbands, alcohol abuse, extra marital affair, dowry harassment, failed love affairs accounted for a small and comparable proportion[10]. Our studies have shown that economic hardship is a significant hardship, India being a developing country and there being an association between depression and lower socioeconomic status, the prevalence of depression is seen across the life span [11]. It could also be explained by cultural differences. The joint family system was in vogue till recently. This provided social security to younger individuals. The breakdown of the joint family and the emergence of the nuclear family could explain the occurrence of depression at younger ages due to reduced family support. It could be the problem of an unmarried girl being pregnant, pressure of independent living, abortion, infertility, wanting male child, discharge against medical advice and referral to a higher center quality of care or cost of medical expense [12]. 


\section{ORIGINAL ARTICLE}

\section{Verbatim accounts from interviewed group about the perception and causes of Suicide survivors}

- Women want divorce she is not getting so she attempt suicide. -2

- Finance or Chit fund cheated by chit fund agent. -1

- Loss of golden ornaments in the marriage function. -1

Failed in the $8^{\text {th }}$ standard, Mother Scolded, Ill treatment by the Teacher, Teased, Pushups, he/she taken poison, tablets, English Language problem in the school /fail.

- His wife had affair with a boy/man, sexual inadequacy. $\quad-5$

- Husband had extra marital relationship with unknown woman. $\quad-6$

- Husbands are alcoholic. -3

- Parents are not accepting inter-caste/religion marriage.

- Every day working in the field it is difficult, because of irregularity of menstrual cycle (7-12days) severe back pain, tiredness. -4

- Step mother's children not sending school, not giving adequate attention to child's health -5

- Second wife, first wife harassing, blackmail and whole property in the hands of first wife not sending her children to school, health, ornaments, cloths.

- illiterate Mother- in- law expect obedience, discipline, not waste food, ill-treatment, teasing of my personality, over talking with neighbors, no freedom

- Crossed 30years she need more sexual satisfaction, concern for her children's future, her husband is not co-operating, she had illegal sexual relation with college student caught by neighbors and wanted to commit suicide.

- More bad dreams in the night, fear, thinking about children's marriage, dowry problem, sleeplessness, I met Talisman, worshiping god increasing heart beats in the night.

- Land property is not distributed by his elder brother.

- Orphans/mother married to unknown person. $-2$

- Because of T.B/HIV illness.

Some of the suicide attempters are not express the reasons because of families fear and the social, legal consequences associated with suicide ${ }^{[6]}$. Cultural attitudes towards the women role in marriage may also partially explain the comparatively higher ratio of female to male suicide found in India as compared to developed countries where arranged marriages are common. The social and familial pressure on women to stay married even in abusive relationships appears to be one of the factors that increase the risk of suicide in women. When dowry expectations are not met, young brides can be harassed to the point where they are driven to suicide [13].

Psycho-social problems and stresses, such as conflict with parents, breakup of a relationship, school difficulties or failure of examinations, social isolation, and physical ailments commonly are observed in young people who attempt suicide [10]. National Crime Record Bureau 
report suggests that family problems are the major reason for suicide among 15-55age groups in our society. While mental illness attributed to 8.5\%, of cases; reasons are recorded as unknown in survived suicide cases. Adversities Including Physical violence, Emotional and sexual abuse can lead to substantially higher risk for suicide [14,15].

We asked question to suicidal survivors whether seriously conceded ending one's life, made a plan about ending one's life 8days to 15days before discharge from our R.L.Jalappa Hospital and Research Center. The outcome was report of suicidal attempters during one year. The reality of women's lives remains invisible to men and women alike and this invisibility persists at all levels beginning with the family to the nation. Although geographically men and women share the same space, they live in different worlds. The mere fact that, women hold up half the sky, does not appear to give them a position of dignity and equality true, that over the years women have made great strides in many areas with notable progress in reducing some gender gaps which we live is characterized by deeply unequal sharing of the burden of adversities between women and men. Sprawling inequalities persists in their access to education, health care, physical and financial resources and opportunities in the political, economic, social and cultural spheres [9].Women do more hours of work both in the family as well as in the agricultural field.

CONCLUSION: Social inequality and poverty have demonstrable adverse effects on health, a social and public health response to suicide is crucial in India, social and public health approach acknowledges that suicide is preventable. The study reveals that life is meaningful and sacred and does not possess its right in itself, but only in God also means dignity is upheld by his freedom which must be used with a sense of responsibility and faith in God. Suicide must be stopped.

Attempted suicides are slowly but steadily assuming the levels of public health problem and multiple factors responsible for attempted suicide were in the age group of 16-55 years male sex, low education level, socio-economic status, illness and family problems. The main limitation of this study is that it is social problems cannot be solved by applying technological solutions. As long as medicine depends on science and science promises hope, these is always hope for mankind and people who make decision should make them judiciously.

\section{REFERENCE:}

1. Vijay Murali and Femi Oyebode, Poverty, Social Inequality and Mental Health. Advances in Psychiatric Treatment 2004; 10:216-24.

2. Soman CR, Safarai S, Ramankutty V, Vijaykumar K and Ajayan K. Suicide in South India: A community based study in Kerala. Indian journal of Psychiatry 2009; 51(4): 261-4.

3. Ogar JN, Agba AM, Ogaboh. Suicide its moral, legal and sociological analysis. Journal of Arts Science \& Commerce International Referred Research Journal 2011; 11(1): 94-102.

4. Yadawad BS, Hareesh Gowda. Is attempted suicide is an offence? Journal of A.F.M 2005; 27(2): 108-11.

5. Monoranjitham, HelenChaeles, Saravanan, Jayakaran R, Abraham S, Jacob KS. Perceptions about suicide: A Qualitative study from southern India. The National Medical Journal of India 2007; 20(4): 176-9.

6. Eddletion. Patterns and problems of deliberate self-poisoning in the developing World 0 Journal of Medicine 2000; 93:715-31. 
7. Hegde RS. Suicide in Rural Community. Indian Journal of Psychiatry 1980; 22: 368-70.

8. Gururaj G, Issac G, Issack MK, Subbakrishna DK, Ranjani R. Risk factors for completed suicide: A case control study from Bangalore, India. International Journal of Injury Control and Safety Promotion 2004; 11: 183-91.

9. Stark CR, Riordan V, Coonor RO. A conceptual model of Suicide in rural areas. The International Electronic journal of Rural and Remote health research, Education practice and policy 2011; 11, 1-11.

10. American academy of pediatrics, Committee on adolescence, Suicide and suicide attempts in adolescence. Pediatrics 2000; 105(4): 871-4.

11. Aravind Pillai, Tedy Andres, Vikram Patel, Violence, Psychological distress and the risk of suicidal behavior in young people. International Journal of Epidemiology 2009; 38: 459-69.

12. Chowdery AN, Banergee A Brahma, Das S, Sarker P, Biswas MK, Sanyal D, Hazra A. Perceptive study of suicidal behavior in Sundarban delta, West Bengal, India. The National Medical Journal of India 2005; 23(4): 201-05.

13. Dinesh Bhugra, Manisha Desai. Attempted suicide in South Asian Women, Journal of Advances in Psychiatric Treatment 2002; 8: 418-23.

14. Subramani Poongothi, Rajendra Pradeepa, Anbhazagan Ganesan, Viswanathan Mohan. Prevalence of Depression in a Large Urban South Indian Population. The Chennai Urban Rural Epidemiology Study 2009; 4(9): 1-14.

15. National crime record bureau 2010.

\section{Source of support: Nil Conflict of Interest: Nil}

Table-1: Age-wise distribution of Suicide attempters

\begin{tabular}{|l|l|l|l|}
\hline Age in years & No of Males & No of Females & Total \\
\hline$<15$ & 0 & 1 & 01 \\
\hline $16-25$ & 26 & 21 & 47 \\
\hline $26-35$ & 10 & 19 & 29 \\
\hline $36-45$ & 11 & 8 & 19 \\
\hline $46-55$ & 8 & 3 & 11 \\
\hline $56-65$ & 1 & 0 & 01 \\
\hline 65 & 1 & 0 & 01 \\
\hline Total & $\mathbf{5 7}$ & $\mathbf{5 2}$ & $\mathbf{1 0 9}$ \\
\hline
\end{tabular}




\section{ORIGINAL ARTICLE}
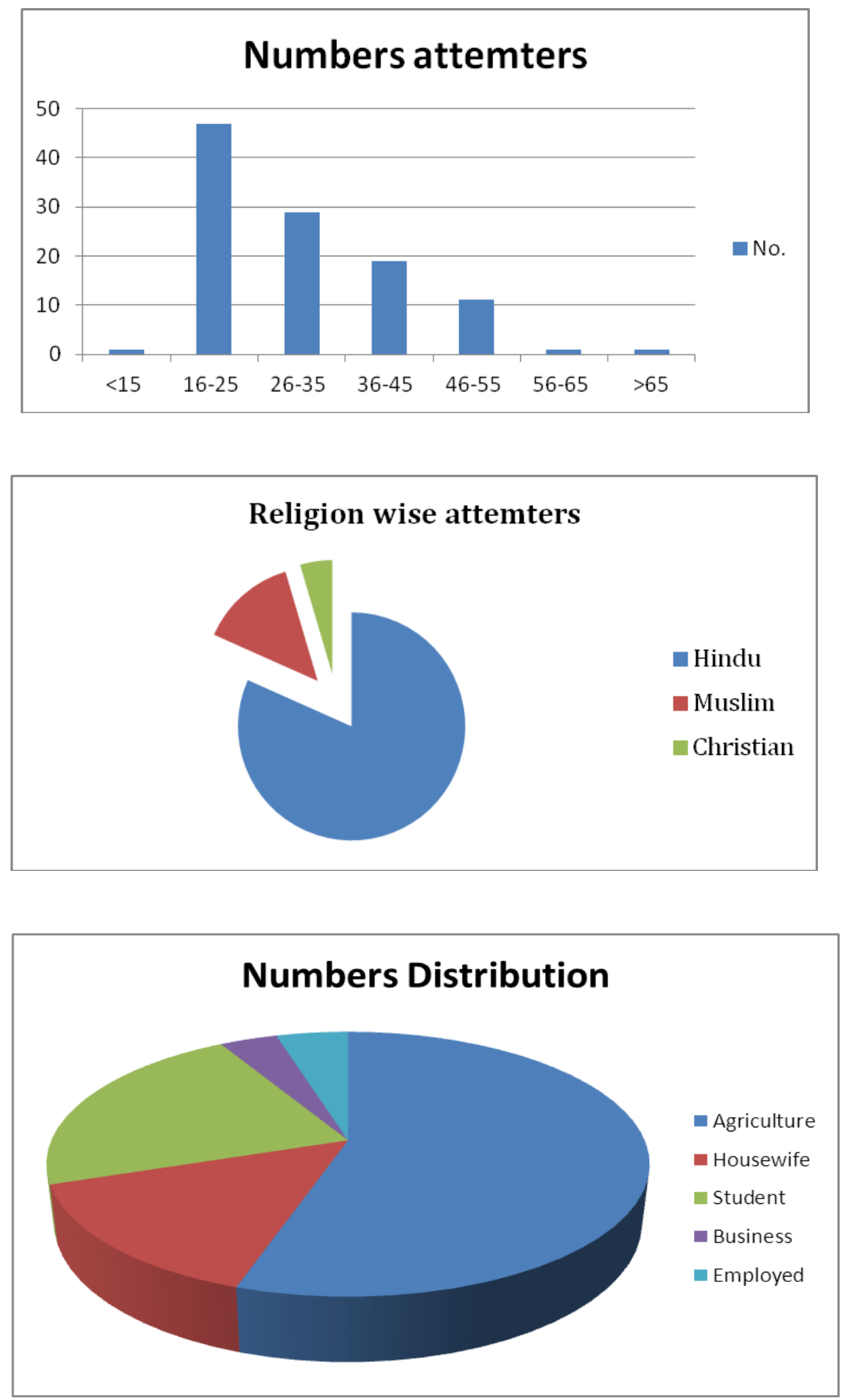


\section{ORIGINAL ARTICLE}

\section{Table 2}

Socio-demographic factors of suicide attempters

\begin{tabular}{|c|c|c|c|c|c|}
\hline & Sex & Male & Female & Total & Percentage \\
\hline \multirow[t]{3}{*}{ Religion } & Hindu & 52 & 37 & 89 & $81.65 \%$ \\
\hline & Muslim & 6 & 9 & 15 & $13.76 \%$ \\
\hline & Christian & 3 & 2 & 5 & $4.58 \%$ \\
\hline \multirow[t]{4}{*}{ Education } & Illiterate & 21 & 48 & 69 & $60.30 \%$ \\
\hline & Upto $5^{\text {th }}$ & 3 & 5 & 8 & $7.33 \%$ \\
\hline & $5^{\text {th }}-10^{\text {th }}$ & 6 & 7 & 13 & $11.92 \%$ \\
\hline & Degree & 10 & 9 & 19 & $17.43 \%$ \\
\hline \multirow[t]{7}{*}{ Income } & Per day & Total & $\%$ & & \\
\hline & Rc $100-200$ & 50 & 1587 & & \\
\hline & $201-300$ & 10 & 9.01 & & \\
\hline & $301-400$ & 5 & 4.58 & & \\
\hline & $401-500$ & 1 & 0.91 & & \\
\hline & $501->$ & 3 & 2.75 & & \\
\hline & No income & 40 & 36.69 & & \\
\hline \multirow[t]{5}{*}{ Occupation } & Agriculture & 60 & $55.04 \%$ & & \\
\hline & Housewife & 16 & $14.67 \%$ & & \\
\hline & Student & 24 & $22.01 \%$ & & \\
\hline & Business & 4 & $3.66 \%$ & & \\
\hline & Employed & 5 & $4.58 \%$ & & \\
\hline \multirow[t]{3}{*}{ Type of family } & Nuclear & 59 & $17.43 \%$ & & \\
\hline & Joint & 35 & $36.69 \%$ & & \\
\hline & Extended & 15 & $9.17 \%$ & & \\
\hline \multirow[t]{2}{*}{ Domicile } & Rural & 90 & $82.56 \%$ & & \\
\hline & Urban & 19 & $17.43 \%$ & & \\
\hline
\end{tabular}

Table 3

Percentage share of the methods adopted in committing suicide during 2010-2011

\begin{tabular}{|l|l|l|}
\hline Methods & No & \% \\
\hline Poising & 47 & 43.11 \\
\hline Alcohol/ And tablets & 29 & 26.60 \\
\hline Drowning & 05 & 04.50 \\
\hline Hanging & 09 & 08.25 \\
\hline Overdose of sleeping pills & 19 & 17.43 \\
\hline Total & $\mathbf{1 0 9}$ & $\mathbf{1 0 0 . 0 0}$ \\
\hline
\end{tabular}




\section{ORIGINAL ARTICLE}

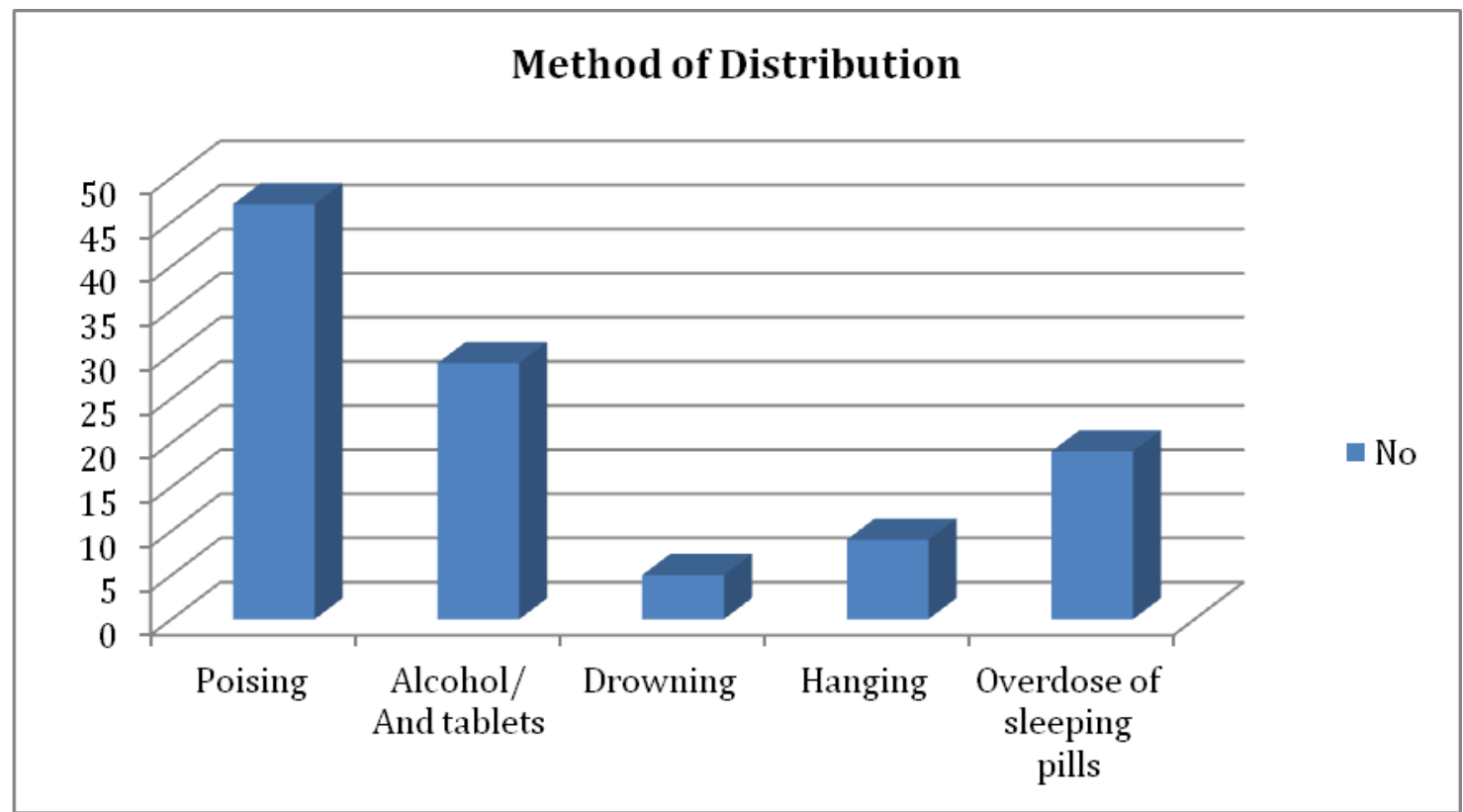

Survived suicide attempters - 65

\begin{tabular}{|l|l|l|}
\hline Sex & No & \% \\
\hline Male & 27 & 41.53 \\
\hline Female & 14 & 21.53 \\
\hline Student & 24 & 36.92 \\
\hline Total & $\mathbf{6 5}$ & $\mathbf{1 0 0 . 0 0}$ \\
\hline
\end{tabular}

